\title{
Genetics of obesity: Gene x Nutrient Interactions
}

\author{
Amelia Marti and J. Alfredo Martinez
}

Department of Physiology and Nutrition. University of Navarra. 31008 Pamplona. Spain.

Corresponding author: J. Alfredo Martínez

Department of Physiology and Nutrition

University of Navarra

31008 Pamplona. Spain

Tel. +34 948-425600 Ext. 6424

Fax. +34 948-425649

E-mail: jalfmtz@unav.es

Running title: Obesity: genetics and diet 


\begin{abstract}
Obesity results from a long-term positive energy balance, in which generelated differences may account for some of the disparities found in weight gain among populations. However, the rising prevalence of obesity in developed and developing societies must reflect lifestyle changes. Despite that the genetic background remains stable over many generations, obesity may be derived from a failure on the homeostasis systems, as a consequence of a dysfunction at the genetic level, which may be affected by changing environmental exposure (dietary habits, sedentarism, etc). In practice, obesity risk at least depends on two important factors, which mutually interact: 1) genetic variants and gene expression changes in candidate genes and 2) exposure to environmental risk factors.

Disagreements among studies involving gene-nutrient interactions may reflect the difficulty of accurate measurement of specific types of dietary macro and micronutrients as well of phenotype assessment rather than a discrepancy in biological relevance. Identification of individuals who are genetically more likely to respond to particular dietary changes may be important for successful intervention in obesity treatment, since gene screening will allow health professionals to tailor-design weight management and dietary guidance in individuals with a genetic predisposition to become obese.
\end{abstract}

Key words: Obesity, energy homeostasis, gene, nutrient, environment, diet. 


\section{Dietary and genetic evolution}

The diversity in dietary habits as well as on genetics traits among human beings has been enormous during the evolutive period of the mankind [1]. There are records of the various diets followed by different populations world-wide. Data from the Stone Age (35000-10000 BC) suggest a low fat intake (<22 as en\%) and a high protein and carbohydrate consumption (about 40 as en\%). The hunters-gatherers lifestyle, which influences the animal or plant food availability sustained humanity for the subsequent 10,000 years, and markedly affected the macronutrient intake (protein 19-35 as en\%), carbohydrate 22-40 as en\%, fat 28-58 as en\%. With advances in agriculture and livestock breeding (10 $000 \mathrm{BC}$ to third millennium), the achieved values during the last century were $10-17$ as en\% for protein, $40-60$ as en\% for carbohydrate and 20-59 as en\% for fat. In most industrialised countries more fat (40-50 en\%), especially saturated fats and less carbohydrates (40-45\% E) were eaten, which was associated to a relevant reduction of starch consumption. Besides, individuals in high and low income countries have experienced important and rapid changes with regard to diet in the last decades, accompanied by a growing prevalence of chronic diseases, including obesity.

However, since the time when man appeared on earth (about $2.4 \times 10^{6}$ years), only minor changes have occurred in the human genome [2]. In fact, a difference in the gene make up of only about $1.6 \%$ was found between modern man and most developed primates. In spite of this overall stability of the human genome, a number of minor alterations in gene structures have been observed. Thus, ethnic and racial differences for various traits have long been recognised. Also, some specific genes have been reported recently to be in connection with the risk of developing obesity, type 2 diabetes or cardiovascular disease. For obese individuals, numerous single polymorphisms have been discovered and characterised in the last two decades [2, 3].

\section{Genetic and dietary influences on obesity at the present time}

Obesity as a complex disease associated to an excessive fat deposition, rarely arise from a unique mutation in a single gene, although there is one relevant example. Monogenic obesity is caused by single mutations in the melanocortin 4 receptor (MC4R) which participates in food intake regulation [4,5]. There are more than 40 functionally relevant MC4R mutations in 2-4\% of extremely obese individuals. 
Commonly, an obese individual will have inherited minor functional mutations or gene variants in genes coding for key proteins involved in the regulation of body weight $[6,7]$. These combined genetic effects account for the biological diversity and in their absence all organisms would respond in a virtually identical manner to the same environmental challenge. Thus, the interaction of functional gene polymorphisms with environmental factors may play a substantial role in the risk of developing obesity.

The research of gene-environment interactions implies that the interplay between genotype and environment deviates from the additive or multiplicative effects of these two factors (Figure 1). This outcome could be a result of chance alone, which highlights the importance of confirmatory findings, but an absence of interaction, could also simply reflect the lack of statistical power (i.e. sample size) in the study to detect such an effect [8]. Genotype-environment interactions ( $\mathrm{G} \times \mathrm{E}$ ) arise when the response of a phenotype (e.g., body weight) to environmental changes (e.g., overfeeding) depends on the individuals genetic background. Most of the genetic epidemiology studies on human obesity have assumed the absence of genotype-environment interactions simply because of the difficulties in assessing such interactive effects in quantitative genetic models.

A working model for the interaction of genetic and environmental factors is presented (Figure 2). A higher obesity risk (represented by a quantitative trait BMI) will arise from the presence of an obesity-related gene variant and environmental influences (high consumption of carbohydrates) for a population carrying a given polymorphism. Indeed, individuals inherited a number of gene variants in key loci, but they make some particular lifestyle choices (e.g. low-fat versus high-fat diets, high versus low levels of physical activity, etc.) affecting weight gain. Thus, while environmental factors may be changed in the short-term, genetic factors can not, but they might interplay. The geneenvironment relationship is a big challenge to be faced for scientist.

\section{Measuring genetic and environmental factors}

There are several well-documented environmental variables that influenced body weight gain and increased obesity risk [9-16]. These variables include excessive calorie intake and sedentary lifestyles. However, these environmental variables are often difficult to quantify with accuracy in free-living individuals. In small intervention studies, it is possible to estimate energy intake and expenditure with a high degree of accuracy, but such experimental trials usually have very little power for genetic studies or for 
screening gene-environmental interactions. Besides, there is large inter-individual diversity in metabolic responses. Generally in intervention studies over $50 \%$ of the subjects show changes in the main direction, a minority of subjects does not exhibit any change, and a few subjects show changes in the opposite direction. This observation clearly indicated that each subject can display both general traits and some particular susceptibility to a given environment (dietary) factor [8].

Moreover, most environmental factors are assessed by questionnaires and may be under-reported (e.g. food intake) or over-reported in the case of exercise. In regard to food intake, daily food records may be useful, but assessing fat content or fatty acid composition is not straightforward [8]. What is desirable is to have biological markers for environmental factors, like plasma measures of by-products that can be objectively quantified as a marker of dietary compliance.

\section{Environmental risk factors: Diet composition}

The content and distribution of the macronutrient intake appears to strongly influence the regulation of food intake and may affect energy utilisation $[13,15]$. The ratio fat to carbohydrate is the main factor that easily causes passive energy overconsumption leading to weight gain [16]. The combination of carbohydrate-sweetened beverages intake and an increasingly sedentary lifestyle, which reduces the metabolic demand for fat as fuel, has been associated to an excessive weight gain. Long-term studies are needed to explore the independent effects of dietary sugars (solid or liquid) and glycemic load on body weight control.

There are more epidemiological data associating high-fat consumption with obesity development, although the results appear to be indicative but no conclusive. A controversial question is whether or not high-fat diets versus low-fat diets with the same equivalent total energy contributed to weight gain [10, 11]. In several weight-loss studies prescribing low carbohydrate diets (moderate to high fat content) as compared to low fat diets, there was no major difference in the average weight reduction [17]. In another trials, a more beneficial lipid profile was found in individuals fed on high fat diet [18]. This heterogeneity supports the idea that there are individual differences in the fat responses, which maybe partially explained by genetic susceptibility and genenutrient interactions. 


\section{Genetic risk factors}

Despite that dietary factors play a significant role in the development of obesity, a number of reports over the last decades have clearly documented a genetic contribution to obesity-related phenotypes as well [2-5]. Obesity and its related traits represent the archetype of a common complex phenotype. The configuration of multiple genes can range from polygenic (i.e. many genes with a relatively small contribution) to oligogenic (i.e. few genes with large measurable effects often expressed on a residual polygenic background). Indeed, it is this oligogenic architecture that warrants all current efforts to map genes for complex phenotypes [19, 20].

In this context, quantitative genetic analyses (twins, siblings and family studies) have shown significant hereditability (an individual's chances of being obese are increased when having obese relatives) with estimates generally ranging from $30-70 \%[4,6]$.

From the late 1980s through the early 1990, segregation analysis was applied in an effort to dissect further the genetic architecture underlying human obesity by attempting to detect the effects of anonymous major genes on obesity related phenotypes. A number of these studies have reported consistent evidence of anonymous major gene effects accounting for as much as $40 \%$ of the variation in BMI or fat mass in a variety of populations [6, 20].

By the early to mid-1990s, researchers began to focus on the goal of identifying the specific genes involved. Initially such effort to identify specific genes influencing complex traits such as those associated with obesity relied on the use of a priori defined candidates genes $[3,19]$. Such candidate genes are selected on the basis of their perceived role or function in biochemical pathways relevant to the specific phenotype of interest (e.g. the structural gene for a circulating protein). The conservation of hypothalamic pathways in rodents and humans has certainly helped in choosing suitable candidates genes. All the spontaneously occurring obesity mutations in mice either have been found to harbour functionally relevant mutations in humans too, or have led to the identification of a system/pathway, in which other genes were found to be mutated. The molecular genetic biology tools recently developed allow the determination of most gene polymorphism from a blood sample, especially single nucleotide polymorphism (SNP). This advance opens a new era, where studies devoted to interaction between diets, metabolic variables, disease risk factors, and gene polymorphism can be conducted. According to the latest version of the Gene Obesity Map 2003 there are more than 430 genes, markers and chromosomal regions involved in body weight 
regulation and obesity development [2]. Moreover, there are 272 studies in obese humans reporting positive associations with 90 candidate genes [2, 3]. Here a selective number of mutations in genes encoding factors regulating food/energy intake as well as factors related to energy expenditure and adipogenesis is reviewed.

\section{Genetic background and obesity}

Body weight regulation and stability depends upon an axis with three interrelated components: food intake, energy expenditure and adipogenesis, although there are still many unknown features concerning fuel homeostasis and energy balance, in which the genetic make-up is involved.

\section{Genes encoding factors regulating food/energy intake}

Hypothalamic and brain stem centres are involved in the regulation of food intake and energy balance, but information on the relevant regulatory factors was scarce before the last decade $[3,19]$. Insulin remained the only candidate with a key role in body weight regulation for a long time until the discovery of leptin. This cytokine-like peptide mainly expressed by adipocytes is now believed to be a key regulator of fat metabolism and energy intake. Leptin is the product of human homologue of mouse "obese" gene, whose homozygous mutation caused hereditary obesity in mice (monogenic) [20-22]. The mechanisms participating in the effects of leptin and other peptides on food intake and body weight regulation are now becoming to be understood. Factors acting at the central nervous system level include: neuropeptide Y, corticotropin releasing hormone, proopiomelanocortin, $\alpha$-melanocyte stimulating hormone, agouti-related protein, melanin-concentrating hormone, cocaine-and amphetamine regulated transcript and other molecules [3, 20]. Interactions among them involving complex neuronal mechanisms, eventually influence behavior and provide important links with neuroendocrine regulation of other vital functions of the organism.

Studies in humans have failed to find leptin or any other mutant gene to be the unique “obesity gene”. Conversely, multifactorial patterns involving the action of numerous polymorphic gene products now look more likely to occur. Evidence is accumulating that most of these genes encoding central peptide factors as well as their receptors (leptin receptors, melanocortin receptors, NPY receptors) are polymorphic [19]. 
Dominant inheritance of obesity conferred by missense, nonsense and frameshift mutations in the melanocortin 4 receptor gene (MC4R) has been extensively reported in many populations including French, English, German, American and Italian individuals [3-4,21-22]. It has been estimated that $4-6 \%$ of extremely obese individuals harbor functionally relevant MC4R mutations. Mutations of the MC4R, two nonsense (Tyr-35Stop, Trp-16-Stop) and several frameshift mutations (732-733insGATT, 631634delCTCT, 47-48insG) can be considered loss-of-function mutations and are associated with dominant inheritance of obesity [21-22]. However, other mutations (i.e.: Thr-11-Ser, Arg-18-Cys) and polymorphisms (Val-103-Ile, Ile-251-Leu) did not modify the function of the MC4R in vitro.

NPY is released from the arcuate hypothalamic nucleus in fasting or hypoglycemia situations and its secretion is inhibited after food intake. The Leu7Pro polymorphism in the NPY gene appears to be involved in lipid metabolism regulation. It is highly prevalent in Caucasians, but not in Japaneses and this suggests that the role of this polymorphism may vary across different population groups. Common polymorphisms in the genes encoding NPY receptors can present another source of variation in this appetite signalling system [19].

A number of peptides synthesised along the gastrointestinal tract also affect food intake. They include ghrelin (orexigenic peptide mainly produced in the stomach), cholecystokinin (produced in the small intestine acting as a short-term satiety signal) and peptide YY3-36 (produced in the colon and suppressing appetite for up to 12 hour). Exploration of these signalling pathways has started and it is becoming clear that polymorphisms in relevant genes may have important functional consequences. One SNP in the highly polymorphic ghrelin gene was found to be associated with fat accumulation [19].

Moreover, the identification of relevant genes related to food preferences has just started. Taste 2 receptors (T2Rs) have been shown to function as bitter taste receptor and T1Rs as putative receptor for sweet taste. There is no information on polymorphism in the T1R family genes, while some SNPs in T2R have been reported [19]. Rapid progress has been made in this field to elucidate the genetic mechanism underlying food preferences. 
Genes encoding factors involved in energy expenditure

The adaptive thermogenesis in humans is closely related to the active mobilisation of lipids from fat tissues and presents special interest in relation to obesity. Central neural pathways responsible for the food intake and energy expenditure regulation are tightly interconnected. The peripheral transmission of central commands to the fat stores is mediated by sympathetic nervous system. The $\beta$-adrenoceptor gene family contains classical obesity candidate genes for its role in the regulation of energy expenditure [3, 23-32].

The $\beta_{2}$-adrenergic receptor gene (ADRB2) encodes a major lipolytic receptor protein in human fat cells. Two common polymorphism of the ADRB2 gene, characterised by an amino acid replacement of arginine by glycine in codon 16 (Arg16Gly) and glutamine by glutamic acid in codon 27 (Gln27Glu) have been explored in diseases such as hypertension and obesity. A relationship between the Arg16Gly polymorphism and an altered function of the ADBR2 has been reported leading to a decreased agonist sensitivity. There is some evidence that the Gln27Glu polymorphism of the ADRB2 may alter lipolytic function contributing to fat accumulation. In men, the 27Glu allele has been associated with increased BMI, subcutaneous fat, elevated leptin and triglycerides levels and increased risk for abdominal obesity [27]. In an intervention study, our group has shown that women homozygotes for the 27Glu allele have impaired the exercise-stimulated lipolysis [23-24]. We also observed an effect modification (interaction) on obesity risk linked to the 27Glu polymorphism by recreational energy expenditure levels. Women carrying of the 27Glu allele and active in their leisure time had a higher BMI compared to non-carriers, being more resistant to lose weight when they were exposed to higher physical activity levels [30].

The $\beta_{3}$-adrenergic receptor (ADRB3) protein plays a role in adipocyte metabolism mediating the rate of lipolysis in response to catecholamines. A common polymorphism in this gene, characterised by an amino acid replacement of tryptophan by arginine at position 64 (Trp64Arg), has been identified and may be linked to lower lipolytic activity accounting for lipid accumulation in adipose tissue $[3,19]$. In regard to BMI, more than nine studies had shown a statistically significant association between BMI and the Trp64Arg polymorphism in a variety of populations. Moreover, 2 meta-analysis examining the effect of this mutation on BMI have been published for Caucasian populations [3, 26]. One includes 2.447 subjects and the significant BMI difference 
among carriers and non-carriers of the mutation is $0.30 \mathrm{~kg} / \mathrm{m}^{2}$. In the second survey on 7399 subjects, the results were not statistically significant.

Clement et al [32] found that morbidly obese subjects with the Arg allele in the ADRB3 gene had a significantly higher weight gain (current weight -weight at 20 years). Similarly, several studies carried out among Mexican American, Japanese and Caucasian women have showed that carriers of the Arg allele had a higher BMI and lower reduction in visceral fat after weight-loss [3]. In a Spanish population we found an age-dependent effect for obesity risk linked to the Try64Arg variant. Carriers of the Arg 64 allele younger than 33 years-old have a significant higher risk of developing obesity. Some authors, however, failed to reproduce the finding in regard to $\beta$ adrenoceptors and further confirmation is required. It is possible that the study of lifestyle influences and other circumstances may unmask the effects of a given gene variant.

Whereas $\beta$-adrenoceptors participate in the regulation of adaptive thermogenesis as a component of sympathetic responses, the ultimate control and modulation of heatgenerating uncoupled respiration at the mitochondrial level is apparently exerted by uncoupling proteins (UCPs). They represent a family of carrier proteins located in the inner layer of mitochondrial membranes [19]. There are different members. UCP 1 mostly expressed in brown adipose tissue with a role in thermogenesis. UCP2 ubiquitously present in many tissues and UCP3 mainly expressed in skeletal muscle and brown adipose tissue. Their putative function as "uncoupling proteins" have been intensively explored [33-34], but their role is still under investigation. Thus, UCP2 and UCP3 appear to be regulators of energy homeostasis, acting as a fatty acid transmembrane transporter in the mitochondria and facilitating protons exchange [3]. These observations have led to the consideration of UCP's as candidate genes for obesity, given their function in the regulation of fuel metabolism.

A number of human studies indicated a relationship between UCP's polymorphisms and exercise efficiency, resting energy expenditure, substrate oxidation, energy metabolism, BMI, leptin, fat accumulation, body weight changes, physical activity and also risk of type 2 diabetes or obesity [33-34]. Several UCP2 gene variants were described: a G/A mutation in the promoter region -866G/A, a valine for alanine substitution at amino acid 55 in exon 4 (Ala55Val) and a 45 base pair insertion/deletion in the untranslated region of exon 8 [34]. The association between these polymorphisms of the UCP2 and various aspects of obesity has been intensively studied. It seems that the allele $G$ in the 
promoter region of UCP2 increases obesity risk, while it affords relative protection for type 2 diabetes [3]. Meanwhile the Ala55Val polymorphism has shown to be associated with increased exercise efficiency [3]. However, results concerning the exon 8 insertion allele of the UCP2 gene have been inconsistent. Although no association with obesity was observed in a number of studies conducted in several populations [33], significant associations between the exon 8 insertion of the UCP2 gene and BMI or fat mass or presence of obesity were found. Thus, in a Spanish sample we also reported a higher obesity risk for carriers of the exon 8 insertion allele of the UCP2 gene after adjusting for lifestyle influences [34].

There are also several UCP3 gene variants potentially involved in weight gain regulation. In linkage studies, some of them have been related to a higher obesity risk [3]. Specifically, the $-55 \mathrm{C} \rightarrow \mathrm{T}$ polymorphism in the promoter region, which has been associated with an elevated body mass index (BMI), an increased level of adiposity or a greater waist-to-hip ratio [3]. However, other authors have not found any relationship between this polymorphism and a higher risk of obesity or changes in metabolic rate. Some studies have even reported an inverse correlation with BMI and the presence of $55 \mathrm{C} \rightarrow \mathrm{T}$ polymorphism [3]. The inconsistencies in some studies may be due to differences in the populations studied, methodological issues and the lack of an adequate consideration of confounding factors (age, gender and lifestyle factors) affecting gene $\mathrm{x}$ nutrient interactions.

\section{Genes encoding factors involved in adipocyte metabolism}

The last group of genes acting in connection with the peripheral regulation of energy expenditure encompasses the transcription factors leading to adipogenesis and adipocyte differentiation. The key actors are peroxisome proliferator-activated receptor $\gamma$, particularly the adipose specific isoform PPARG2. In a meta-analysis with 19,136 subjects, a positive association between BMI and the Pro12Ala polymorphism of the PPARG2 gene was found [35]. In a Spanish group, the frequency of the Ala allele was similar to other Caucasian populations, but higher in obese subjects (allelic frequency 0.13) compared to controls (0.08) suggesting that this polymorphism was associated with obesity [36]. There is also information on the functional role of PPARG gene variants and some mutants proteins appear to have a reduced activity [3].

Discrepancies among investigators on the effect of a given polymorphism on obesityphenotypes may be explained by the environmental influences. The lifestyle factors 
specially those related to diet (macronutrient composition or total energy intake) can interact with the genetics factor and may mask the genotype influences.

\section{Strategies for searching gene-diet interactions in regard to obesity phenotypes}

It is possible to investigate gene-diet interactions in human obesity using either intervention or epidemiological observational studies. The objective is to address the influence of each environmental factor in regard to the whole genome or specific gene variants influence.

Four methods can be used to provide evidence for $G \times \mathrm{E}$ effects in humans when molecular markers are available [2, 9]. The first is to compare the influence of a gene on a given phenotype between populations of different ethnic and cultural backgrounds. The second method consists of comparing the effect of a gene between subgroups of individuals within the same population, but categorised on the basis of variables that can potentially affect the phenotype under study. In the third method, the response to an environmental stimulus is investigated among individuals with different genotypes at a given gene or marker locus. A fourth method is based on the "variability gene", which contributes to the susceptibility to changes in the environment.

The overfeeding approach represents another type of intervention trial. Thus, Bouchard et al [37] performed studies in monozygotic twins after a long-term standardised overfeeding period (100 days). The volunteers, 12 pairs of identical male twins, were fed with a diet containing 1000 kcal above their baseline measured energy intake, composed of $50 \%$ carbohydrates, 35\% fat, and $15 \%$ protein. After the overfeeding period the weight gain achieved was $8.1 \mathrm{~kg}$ with a $67 \%$ of weight gain attributable to fat mass. Interestingly, the within-pair resemblance for changes in body weight and fat mass and other adiposity markers was statistically significant. To dissect the molecular bases of such genotype-overfeeding interaction, 40 candidate gene variants were studied [38]. The major association between body weight gain or subcutaneous fat mass and overfeeding was seen for the Gln27Glu polymorphism of the ADRB2. Surprisingly, non-carriers of the Glu allele were heavier (7\% increase of body weight) and had higher subcutaneous fat gain than Glu carriers [38].

The literature regarding gene and diet interactions for disease risk profile is still poor. The most intensively studied loci are those related to cardiovascular disease risk such as lipase and apolipoproteins gene variants [40-42]. The polymorphisms in these genes 
determined plasma lipid responses to dietary intake. Other gene variants like those corresponding to cholesterol ester transfer protein (CETP) and fatty-acid binding protein- 2 (FABP2) are starting to show indications of significant effects towards disease risk [43]. Specifically, the Ala54 Thr FABP2 variant appears to be associated with insulin sensitivity, only in individuals consuming a high-fat diet. A recent paper reported that postpandrial lipemia (higher chylomicron cholesterol after olive oil only)in subjects with the Thr 54 variant of the FABP2 is dependent on the type of fat ingested [44].

Few attempts were conducted to examine the influence of gene-diet interactions on obesity-related phenotypes. Using case-control designs, Nieters et al [45] showed that allelic variants of leptin and tumor necrosis factor $\alpha$ (TNF $\alpha)$ may affect obesity risk depending on the levels of intake of n-6 fatty acids. While, Martinez et al [36] found a significant interaction between obesity risk and high levels of carbohydrates consumption (above $49 \%$ of total energy) for subjects carriers of the Glu allele of the ADRB2. Interestingly, a set of research papers have been devoted to the interplay of the polymorphism Pro12 Ala of the PPARG2 gene and dietary patterns in regard to obesity phenotypes (Table 1). In vivo ligands for PPARG2 are thought to include a variety of fatty acids according to their chain length or degree of saturation. Luan et al [46] reported an inverse interaction between dietary polyunsaturated fat to saturated fat ratio (P:S ratio) with BMI among 12 Ala carriers. The mean BMI in Ala carriers is greater than in Pro/Pro homozygotes when P:S ratio is low. Memisoglu et al [47] in a largersize women population indicated the presence of associations between intake of total fat and BMI in regard to PPARG2 genotypes. They observed a significant trend between total fat intake and BMI, but only in Pro/Pro individuals [47]. However, intake of saturated fat was directly associated to increased BMI in carriers and non-carrier of the 12Ala variant, and intake of monounsaturated fat was inversely associated with BMI only in 12 Ala carriers of the PPARG2 polymorphism [48].

In a case-control design, Nieters at al [45] observed a higher risk of obesity for carriers of the Ala 12 variant with increasing intake of arachidonic acid, whereas Marti et al [36] reported an increased obesity risk for carriers of the 12 Ala allele when consuming more than $49 \%$ of total energy from carbohydrates.

Other approach to demonstrate the mutual interactions between the genetic background and dietary patterns have consisted in the nutritional intervention on obese subjects designed to lose weight, whose outcome have been dependent on the occurrence of 
some polymorphism in candidate gene. Positive evidences of this interplay have been obtained for the Trp64Arg polymorphism affecting the $\beta 3$ adrenergic receptor gene [49, 50] and for other gene polymorphisms such as those concerning the serotonin receptor [51], PPAR 2 [48, 52], leptin receptor [53], UCPs [54], in which the weight reduction was influenced by the genetic make up [55, 56].

\section{Summary}

Obesity is a major chronic disease of multifactorial origin, which is dependent of modifiable (lifestyle) and uncontrollable risk factors (genes, age, family history, etc) affecting the phenotype outcome $[57,58]$. Considerable research now indicates that genetics is a factor in determining the individuals risk to obesity and at least 430 genes or chromosomal markers have been identified to be putatively involved in body weight regulation [2]. Furthermore, diet and genetics interact in numerous ways and mechanisms to influence obesity onset (appetite, energy expenditure, adipogenesis, etc). Indeed, genetics influences the human body's physiological response, while diet influences the expression of genes related to energy homeostasis [57].

The discrepancy among studies may reflect the difficulty of accurate measurements of specific types of dietary macro and micronutrients as well on the phenotype assessment rather than a discrepancy with biological relevance. Moreover, the different observations suggest that at least dietary counselling may need to be taken into consideration concerning the PPARG2 genotype. Identification of individuals who are genetically more likely to respond to particular dietary changes may be important for successful intervention in obesity treatment, since gene screening will allow health professionals to tailor-design and selective dietary counselling in individuals with genetic predisposition to be obese [59].

Acknowledgements: The authors wish to thank the European Commission, the Government of Navarra and the University of Navarra for the financial contribution and scientific support. 


\section{References}

1. Cordain, L., Miller, J.B., Eaton, S.B., Mann, N., Holt, S.H. and Speth, J.D. (2000) Plant-animal subsistence ratios and macronutrient energy estimations in worldwide hunter-gatherer diets. Am J Clin Nutr. 71, 682-692.

2. Snyder, E.E., Walts, B., Perusse, L., Chagnon,Y.C., Weisnagel, S.J., Rankinen, T. and Bouchard, C. (2004) The human obesity gene map: the 2003 update. Obes. Res. 12, 369-439.

3. Ochoa, M.C., Marti, A. and Martinez, J.A. (2004) [Obesity studies in candidate genes] Med. Clin. (Barc). 122,542-551.

4. Hebebrand, J., Friedel, S., Schauble, N., Geller, F. and Hinney, A. (2003) Perspectives: molecular genetic research in human obesity. Obes. Rev. 4, 139-146.

5. Marti, A., Corbalan, M.C., Forga, L., Martinez, J.A., Hinney, A. and Hebebrand, J. (2003) Presence of new mutation in the melanocortin-4 receptor in a Spanish population. Int. J. Obes. Relat. Metab. Disord. 27, 385-388.

6. Perusse, L. and Bouchard, C. (1999) Genotype-environment interaction in human obesity. Nutr. Rev. 57 (Pt 2), S31-S37.

7. Martinez, J.A. (2000) Obesity in young Europeans: genetic and environmental influences. Eur. J. Clin. Nutr. 54 Suppl 1, S56-S60.

8. Talmud PJ. (2004) How to identify gene-environment interactions in a multifactorial disease: CHD as an example. Proc. Nutr. Soc. 63, 5-10.

9. Perusse, L. and Bouchard, C. (2000) Gene-diet interactions in obesity. Am. J. Clin. Nutr. 72(5 Suppl), 1285S-1290S.

10. Bray, G.A. (2004) The epidemic of obesity and changes in food intake: the Fluoride Hypothesis. Physiol. Behav. 82, 115-21.

11. Martinez, J.A. (2000) Body-weight regulation: causes of obesity. Proc. Nutr. Soc. 59, 337-345.

12. Martinez-Gonzalez, M.A., Martinez, J.A., Hu, F.B., Gibney, M.J. and Kearney. J. (1999) Physical inactivity, sedentary lifestyle and obesity in the European Union. Int. J. Obes. Relat. Metab. Disord. 23, 1192-1201.

13. Buchholz, A.C. and Schoeller, D.A. (2004) Is a calorie a calorie? Am. J. Clin. Nutr. 79, 899S-906S.

14. Drapeau, V., Despres, J.P., Bouchard, C., Allard, L., Fournier, G., Leblanc, C. and Tremblay, A. (2004) Modifications in food-group consumption are related to long-term body-weight changes. Am. J. Clin. Nutr. 80, 29-37.

15. Heymsfield, S.B. (2004) The weight debate: balancing food composition and physical activity. Am. J. Clin. Nutr. 79, 897S-898S.

16. Saris, W.H. (2003) Sugars, energy metabolism, and body weight control. Am. J. Clin. Nutr. 78, 850S-857S.

17. Samaha, F.F., Iqbal, N., Seshadri, P., Chicano, K.L., Daily, D.A., McGrory, J., Williams, T., Williams, M., Gracely, E.J. and Stern, L. (2003) A low-carbohydrate as compared with a low-fat diet in severe obesity. N. Engl. J. Med. 348, 2074-2081.

18. Stern, L., Iqbal, N., Seshadri, P., Chicano, K.L., Daily, D.A., McGrory, J., Williams, M., Gracely, E.J. and Samaha, F.F. (2004) The effects of low-carbohydrate versus conventional weight loss diets in severely obese adults: one-year follow-up of a randomized trial. Ann. Intern. Med. 140, 778-785.

19. Loktionov, A. (2003) Common gene polymorphisms and nutrition: emerging links with pathogenesis of multifactorial chronic diseases (review). J. Nutr. Biochem. 14, 426-451.

20. Comuzzie, A.G. (2002) The emerging pattern of the genetic contribution to human obesity. Best. Pract. Res. Clin. Endocrinol. Metab. 16, 611-621.

21. Farooqi, I.S. and O'Rahilly, S. (2004) Monogenic human obesity syndromes. Recent. Prog. Horm. Res. 59, 409-424.

22. Lubrano-Berthelier, C., Cavazos, M., Dubern, B., Shapiro, A., Stunff, C.L., Zhang, S., Picart, F., Govaerts, C., Froguel, P., Bougneres, P., Clement, K. and Vaisse, C. (2003) Molecular genetics of human obesity-associated MC4R mutations. Ann. N. Y. Acad. Sci 994, 49-57.

23. Macho-Azcarate, T., Marti, A., Gonzalez, A., Martinez, J.A. and Ibanez, J. (2002) Gln27Glu polymorphism in the beta2 adrenergic receptor gene and lipid metabolism during exercise in obese women. Int. J. Obes. Relat. Metab. Disord. 26, 1434-1441.

24. Macho-Azcarate, T., Calabuig, J., Marti, A. and Martinez, J.A. (2002) A maximal effort trial in obese women carrying the beta2-adrenoceptor Gln27Glu polymorphism. J. Physiol. Biochem. 58, 103-108.

25. Forga, L., Corbalán, M.S., Palacios, M., Rivero, A., Marti, A., Martinez-Gonzalez, M.A. and Martínez, J.A. (2002) $\beta_{2}$ or $\beta_{3}$ receptor gene polymorphisms and cardiovascular risk. Proc End Soc 525-528. 
26. Corbalan, M.S., Marti, A., Forga, L., Martinez-Gonzalez, M.A. and Martinez, J.A. (2002) The Risk of Obesity and the Trp64Arg Polymorphism of the beta(3)-Adrenergic Receptor: Effect Modification by Age. Ann. Nutr. Metab. 46, 152-158.

27. Corbalan, M.S., Marti, A., Forga, L., Martinez-Gonzalez, M.A. and Martinez, J.A. (2002) beta(2)Adrenergic receptor mutation and abdominal obesity risk: Effect modification by gender and HDLcholesterol. Eur. J. Nutr. 41,114-118.

28. Macho-Azcarate, T., Marti, A., Calabuig, J. and Martinez, J.A. (2003) Basal fat oxidation and after a peak oxygen consumption test in obese women with a beta2 adrenoceptor gene polymorphism. J. Nutr. Biochem. 14, 275-279.

29. Martinez, J.A., Corbalan, M.S., Sanchez-Villegas, A., Forga, L., Marti, A. and Martinez-Gonzalez, M.A. (2003) Obesity risk is associated with carbohydrate intake in women carrying the Gln27Glu beta2-adrenoceptor polymorphism. J. Nutr. 133, 2549-2554.

30. Corbalan, M.S., Marti, A., Forga, L., Martinez-Gonzalez, M.A. and Martinez, J.A. (2002) The 27Glu polymorphism of the $\beta_{2}$-adrenergic receptor interacts with physical activity influencing obesity risk among female subjects. Clin. Genet. 61, 305-307.

31. Marti, A., Corbalan, M.S., Martinez-Gonzalez, M.A. and Martinez, J.A. (2002) TRP64ARG polymorphism of the beta3-adrenergic receptor gene and obesity risk: effect modification by a sedentary lifestyle. Diabetes Obes. Metab. 4, 428-430.

32. Clement, K., Vaisse, C., Manning, B.S., Basdevant, A., Guy-Grand, B., Ruiz, J., Silver, K.D., Shuldiner, A.R., Froguel, P. and Strosberg, A.D. (1995) Genetic variation in the beta 3-adrenergic receptor and an increased capacity to gain weight in patients with morbid obesity. N. Engl. J. Med. 333, 352-354.

33. Forga, L., Corbalan, M.S., Marti, A., Fuentes, C., Martinez-Gonzalez, M.A. and Martinez, J.A. (2003) [Influence of the polymorphism 03826 A --> G in the UCP1 gene on the components of metabolic syndrome] An. Sist. Sanit. Navar. 26, 231-236.

34. Marti, A., Corbalan, M.S., Forga, L., Martinez-Gonzalez, M.A. and Martinez, J.A. (2004) Higher obesity risk associated with the exon-8 insertion of the UCP2 gene in a Spanish case-control study. Nutrition 20, 498-501.

35. Masud, S., Ye, S. and S.A.S. Group. (2003) Effect of the peroxisome proliferator activated receptorgamma gene Pro12Ala variant on body mass index: a meta-analysis. J. Med. Genet. 40, 773-780.

36. Marti, A., Corbalan, M.S., Martinez-Gonzalez, M.A., Forga, L. and Martinez, J.A. (2002) CHO intake alters obesity risk associated with Pro12Ala polymorphism of PPARgamma gene. J. Physiol. Biochem. 58, 219-220.

37. Ukkola, O. and Bouchard, C. (2004) Role of candidate genes in the responses to long-term overfeeding: review of findings. Obes. Rev. 5, 3-12.

38. Ukkola, O., Tremblay, A., Sun, G., Chagnon, Y.C. and Bouchard, C. (2001) Genetic variation at the uncoupling protein 1, 2 and 3 loci and the response to long-term overfeeding. Eur. J. Clin. Nutr. 55, 1008-1015.

39. Deeb, S.S., Zambon, A., Carr, M.C., Ayyobi, A.F. and Brunzell, J.D. (2003) Hepatic lipase and dyslipidemia: interactions among genetic variants, obesity, gender, and diet. J. Lipid. Res. 44, 12791286.

40. Brown, S., Ordovas, J.M. and Campos, H. (2003) Interaction between the APOC3 gene promoter polymorphisms, saturated fat intake and plasma lipoproteins. Atherosclerosis. 170, 307-313.

41. Ordovas, J.M., Corella, D., Demissie, S., Cupples, L.A., Couture, P., Coltell, O., Wilson, P.W., Schaefer, E.J. and Tucker, K.L. (2002) Dietary fat intake determines the effect of a common polymorphism in the hepatic lipase gene promoter on high-density lipoprotein metabolism: evidence of a strong dose effect in this gene-nutrient interaction in the Framingham Study. Circulation. 106, 2315-2321.

42. Ordovas, J.M. (2002) Gene-diet interaction and plasma lipid responses to dietary intervention. Biochem. Soc. Trans. 30, 68-73.

43. Weiss, E.P., Brown, M.D., Shuldiner, A.R. and Hagberg, J.M. (2002) Fatty acid binding protein-2 gene variants and insulin resistance: gene and gene-environment interaction effects. Physiol. Genomics. 10, 145-157.

44. Dworatzek, P.D., Hegele, R.A. and Wolever, T.M. (2004) Postprandial lipemia in subjects with the threonine 54 variant of the fatty acid-binding protein 2 gene is dependent on the type of fat ingested. Am. J. Clin. Nutr. 79, 1110-1117.

45. Nieters, A., Becker, N. and Linseisen, J. (2002) Polymorphisms in candidate obesity genes and their interaction with dietary intake of n-6 polyunsaturated fatty acids affect obesity risk in a sub-sample of the EPIC-Heidelberg cohort. Eur. J. Nutr. 41, 210-221. 
46. Luan, J., Browne, P.O., Harding, A.H., Halsall, D.J., O'Rahilly, S., Chatterjee, V.K. and Wareham, N.J. (2001) Evidence for gene-nutrient interaction at the PPARgamma locus. Diabetes. 50, 686-689.

47. Memisoglu, A., Hu, F.B., Hankinson, S.E., Manson, J.E., De Vivo, I., Willett, W.C. and Hunter, D.J. (2003) Interaction between a peroxisome proliferator-activated receptor gamma gene polymorphism and dietary fat intake in relation to body mass. Hum. Mol. Genet. 12, 2923-2929.

48. Robitaille, J., Despres, J.P., Perusse, L. and Vohl, M.C. (2003) The PPAR-gamma P12A polymorphism modulates the relationship between dietary fat intake and components of the metabolic syndrome: results from the Quebec Family Study. Clin. Genet. 63, 109-116.

49. Nakamura, M., Tanaka, M., Abe, S., Itoh, K., Imai, K., Masuda, T. and Nakao, H. (2000) Association between beta-3-adrenergic receptor polymorphism and lower reduction in the ratio of visceral fat to subcutaneous fat area during weight loss in Japanese obese women. Nutr. Res. 20, 25-34.

50. Shiwaku, K., Nogi, A., Anuurad, E., Kitajima, K., Enkhmaa, B., Shimono, K. and Yamane, Y. (2003) Difficulty in losing weight by behavioral intervention for women with Trp64Arg polymorphism of the beta3-adrenergic receptor gene. Int J Obes Relat Metab Disord. 27, 1028-36.

51. Pooley, E.C., Fairburn, C.G., Cooper, Z., Sodhi, M.S., Cowen, P.J. and Harrison, P.J. (2004) A 5HT2C receptor promoter polymorphism (HTR2C - 759C/T) is associated with obesity in women, and with resistance to weight loss in heterozygotes. Am J Med Genet. 126B: 124-127.

52. Nicklas, B.J., van Rossum, E.F., Berman, D.M., Ryan, A.S., Dennis, K.E. and Shuldiner, A.R. (2001) Genetic variation in the peroxisome proliferator-activated receptor-gamma2 gene (Pro12Ala) affects metabolic responses to weight loss and subsequent weight regain. Diabetes. 50, 2172-2176.

53. Mammes, O., Aubert, R., Betoulle, D., Pean, F., Herbeth, B., Visvikis, S., Siest, G. and Fumeron, F. (2001) LEPR gene polymorphisms: associations with overweight, fat mass and response to diet in women. Eur J Clin Invest. 31, 398-404.

54. Fumeron, F., Durack-Bown, I., Betoulle, D., Cassard-Doulcier, A.M., Tuzet, S., Bouillaud, F., Melchior, J.C., Ricquier, D. and Apfelbaum, M. (1996) Polymorphisms of uncoupling protein (UCP) and beta 3 adrenoreceptor genes in obese people submitted to a low calorie diet. Int J Obes Relat Metab Disord. 20, 1051-1054.

55. Moreno-Aliaga, M.J., Santos, J.L., Marti, A. and Martínez, J.A. (2004) Does weight loss prognosis depend on genetic make up? Obes. Reviews. (in press).

56. Verdich, C. and Sorensen, T.I.A. Nutrient-gene interactions in the control of obesity? in Functional foods, ageing and degenerative disease. Edited by C Remacle and B Reusens. CRC Boca Raton (2004).

57. Bray, G.A. and Bouchard, C In Handbook of obesity. Edited by Bray, G.A. and Bouchard, C. Marcel Dekker, Inc. New York (2004).

58. Hill, J.O., Wyatt, H.R., Reed, G.W. and Peters, J.C. (2003) Obesity and the environment: where do we go from here? Science. 299, 853-855.

59. Miller, G.D. and Groziak SM. (1997) Diet and gene interactions. J Am Coll Nutr. 16, 293-295. 
TABLE 1: Summary of positive findings regarding interactions between the polymorphism Pro12Ala of the PPARG2 and dietary intake on obesity phenotypes.

\begin{tabular}{|c|c|c|c|}
\hline STUDY & $\begin{array}{l}\text { POPULATION } \\
\text { Total (Male/Women) }\end{array}$ & $\begin{array}{l}\text { PREVALENCE } \\
\text { (\% Ala homozygous) }\end{array}$ & INTERACTION BETWEEN \\
\hline Nieters et al 2002 & $\begin{array}{l}308(154 / 154) \\
\text { Age-sex-matched } \\
\text { C: } \text { BMI<25 O: } \text { BMI }>35\end{array}$ & $1.9 \%$ & $\begin{array}{l}\text { High arachidonic acid intake for increased obesity risk } \\
\qquad(p=0.062)\end{array}$ \\
\hline
\end{tabular}


Figure 1. Different approaches to identify gene $\mathrm{x}$ nutrient interaction based on the assessment of the obesity risk (OR) or a phenotype marker (BMI).

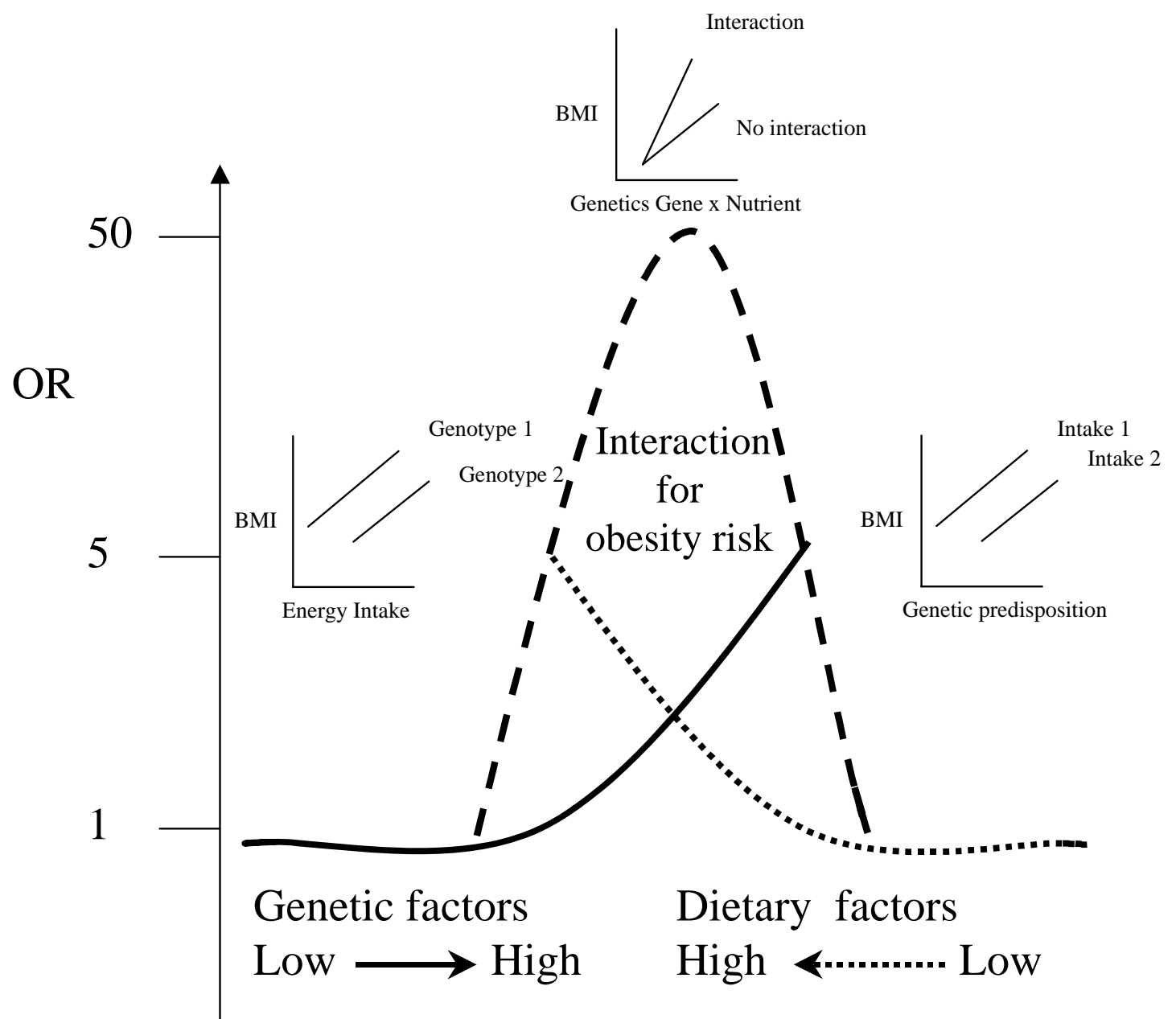


Figure 2. A working model for the interaction of genetic and environmental factors involving a higher obesity risk (represented by a quantitative trait BMI) as affected by the dietary intake (high consumption of carbohydrates) in a population carrying a given polymorphism (PPAR).

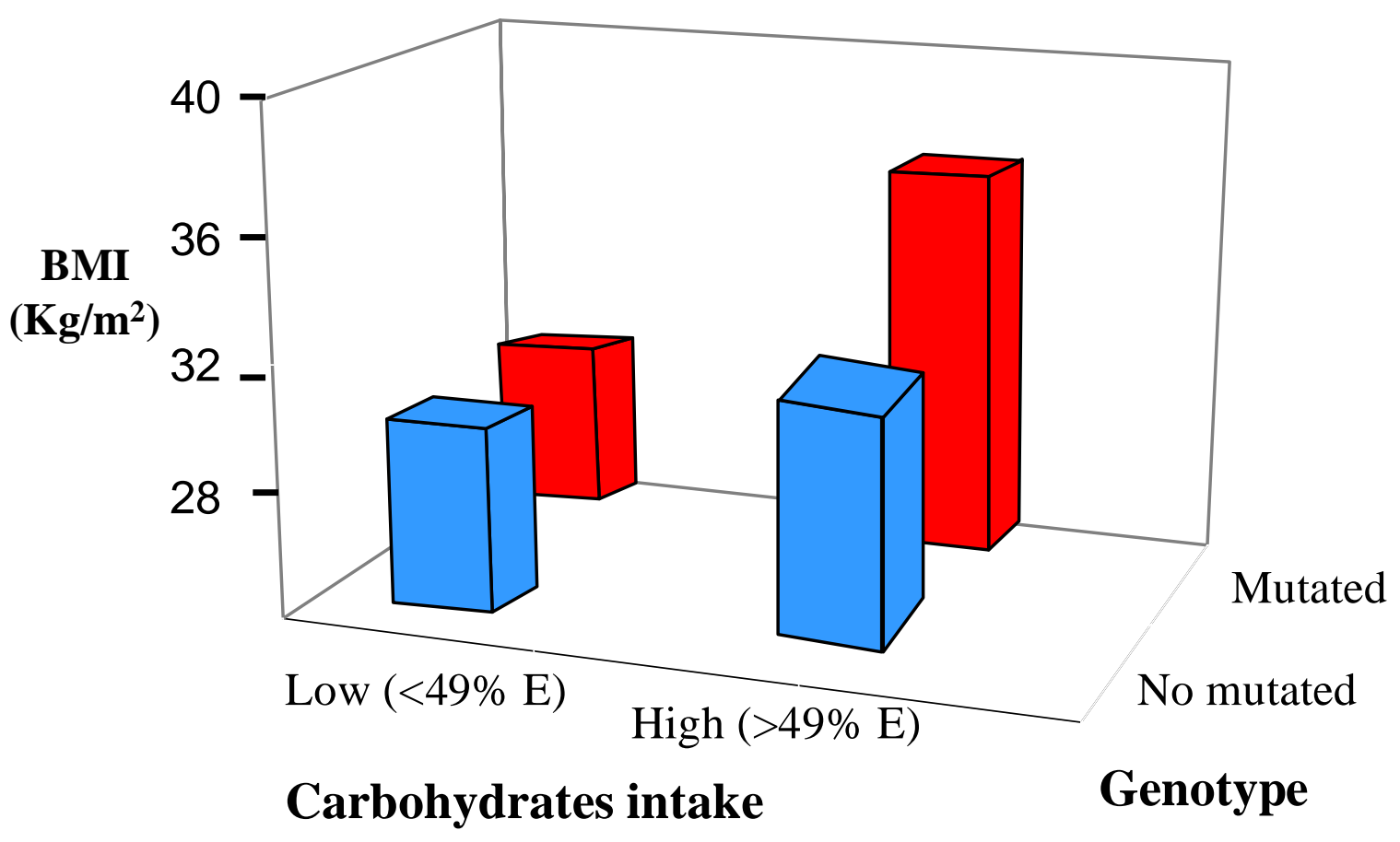

